Research Article

\title{
Clinical Features and Resistance to Entecavir Monotherapy of Patients with Hepatitis B
}

\author{
Hideo Takayama $\mathbb{D D}^{1}$ Takuya Komura $\mathbb{D}^{1},{ }^{1}$ Takashi Kagaya, ${ }^{1}$ Saiho Sugimoto, ${ }^{2}$ \\ Noriaki Orita, ${ }^{2}$ Yoshiro Asahina, ${ }^{2}$ Masashi Nishikawa, ${ }^{1}$ Hajime Ohta, ${ }^{3}$ Shuichi Kaneko, ${ }^{2}$ \\ and Masashi Unoura ${ }^{1}$ \\ ${ }^{1}$ Division of Gastroenterology NHO, Kanazawa Medical Center, 1-1 Shimoishibikimachi, Kanazawa, Ishikawa 920-8650, Japan \\ ${ }^{2}$ System Biology, Kanazawa University, Graduate School of Medical Science, Kanazawa, Japan \\ ${ }^{3}$ Municipal Tsuruga Hospital, Tsuruga, Japan
}

Correspondence should be addressed to Hideo Takayama; hideo.takayama36@gmail.com

Received 13 April 2021; Revised 18 July 2021; Accepted 2 August 2021; Published 12 August 2021

Academic Editor: Alessandro Granito

\begin{abstract}
Copyright (c) 2021 Hideo Takayama et al. This is an open access article distributed under the Creative Commons Attribution License, which permits unrestricted use, distribution, and reproduction in any medium, provided the original work is properly cited.
\end{abstract}

\begin{abstract}
Aim. Hepatitis B virus (HBV) infection is a major public health concern worldwide. Entecavir (ETV), a first-line nucleos(t)ide analogue (NA) for HBV, has a low risk of resistance. We evaluated the efficacy of ETV monotherapy, ratio of ETV-resistant, and the clinical features of patients with ETV resistance. Methods. A total of 130 patients ( 72 males, 58 females; mean age, $61 \pm 15$ years) were divided into a NA-naïve group $(n=108)$ and NA-experienced group $(n=22)$. We examined the clinical outcomes of ETV monotherapy and associated factors. We also assessed the clinical features of 15 patients with resistance to ETV (mean, $51.0 \pm 27.4$ weeks). Results. Among the 130 patients, $94.1 \%$ achieved ALT normalization and $63.6 \%$ achieved serum HBV DNA negativity after ETV monotherapy for 96 weeks. Of the patients in the NA-naïve group, 93.1\% and $60.4 \%$ achieved ALT normalization and HBV DNA negativity, respectively. Of the patients in the NA-experienced group, $100 \%$ and $74.9 \%$ achieved ALT normalization and HBV DNA negativity, respectively. Compared to patients on ETV continuously, 15 ETV-resistant patients had a higher baseline HBV viral load. There was a significant difference in the time to HBV DNA negativity, but not ALT normalization after ETV monotherapy in these groups. Rescue treatment with other NAs led to ALT normalization in all of these patients, but not HBV DNA negativity. Conclusions. ETV monotherapy has a long-term clinical efficacy. While some patients especially with HBV DNA high viral load developed ETV resistance, rescue treatment led to ALT normalization in these patients.
\end{abstract}

\section{Introduction}

Hepatitis B virus (HBV) infection is a leading cause of chronic hepatitis, liver cirrhosis, and hepatocellular carcinoma (HCC), all of which ultimately result in death [1]. Over 300 million people are chronically infected with $\mathrm{HBV}$ worldwide [2]. Treatment of HBV leads to prevention of complications of chronic liver diseases such as HCC [3]. It has also been reported that there is a potential effect of alcohol intake on the progression of liver disease in patients with HBV hepatitis [4]. The American Association for the Study of the Liver (AASLD) [5], European Association for the Study of the Liver (EASL) [6], Asian Pacific Association for the Study of the Liver (APASL) [7], and Japan Society of Hepatology (JSH) [8] have published guidelines for diagnosing, preventing, and managing $\mathrm{HBV}$ infection. The majority of patients with persistent HBV infection may not require antiviral therapy, the indications for which are based on age, histological progression, the alanine aminotransferase (ALT) level, and the HBV DNA level [5-8]. Therefore, therapy should be considered in patients with more active or advanced liver disease and in those likely to respond in accordance with defined treatment endpoints. Treatment algorithms have been developed to assist in the identification of suitable candidates for treatment and to determine when to initiate treatment [5-8]. 
Six antiviral nucleos(t)ide analogues (NAs)-lamivudine (LAM), adefovir dipivoxil (ADV), entecavir (ETV), telbivudine (LdT), tenofovir disoproxil fumarate (TDF) and tenofovir alafenamide fumarate (TAF) - have been approved for chronic HBV hepatitis. All six are HBV polymerase/reverse transcriptase (RT) inhibitors and suppress HBV replication $[9,10]$. Because ETV, like TDF and TAF, decreases the HBV viral load, promotes ALT normalization, and has a low risk of viral resistance, it has been used as a first-line therapy $[5,11,12]$. ETV $(0.5 \mathrm{mg}$ per day) has been approved for treatment-naïve cases in Japan since 2006 [8]. A major concern with long-term NA treatment is antiviral resistance mutations [13]. Because drug-resistant mutant HBV populations expand via replication, antiviral therapy should aim to suppress viral replication as completely and rapidly as possible $[9,10]$. However, the clinical features of patients with ETV resistance are unclear.

We retrospectively examined the outcomes of patients with $\mathrm{HBV}$ hepatitis who received ETV monotherapy and the clinical features and rescue treatment outcomes of patients with ETV resistance.

\section{Methods}

This study was performed according to the ethical guidelines of the Declaration of Helsinki (1964, and its later amendments); the protocol was approved by the Institutional Review Board of NHO Kanazawa Medical Center (Kanazawa, Japan).

2.1. Patients. A total of 316 patients with $\mathrm{HBV}$ hepatitis received NA therapy at NHO Kanazawa Medical Center from December 2000 to December 2019. Of them, 130 patients with HBV hepatitis (72 males, 58 females; mean age, $60.9 \pm 15.0$ years; mean follow-up duration, 69.4 (0-163) months) who received ETV monotherapy were enrolled in this study after providing informed consent. We have confirmed that there is no coinfection with $\mathrm{HCV}$ in this study.

We applied NA therapy for patients with HBV hepatitis according to the JSH guidelines for the management of $\mathrm{HBV}$ infection [8]. The treatment indications are based on the serum ALT level, HBV DNA level, and extent of liver fibrosis.

We defined ETV resistance as virological breakthrough ( $>1 \log _{10}$ increase in the serum HBV DNA level from nadir after an initial virological response) or insufficient viral suppression [5]. ETV monotherapy was applied for NAnaïve and NA-experienced patients.

2.2. Clinical Features. At admission, we evaluated the following factors: age, gender, baseline aspartate aminotransferase level (AST), highest ALT level, prior NA experience, and HBsAg positivity. Data on the baseline HBV DNA and HBcrAg levels, viral genotype, extent of liver fibrosis, and response to ETV monotherapy are given in Table 1.
2.3. Genotypic Resistance Assay. The PCR-invader assay (BML Corp., Tokyo, Japan) was used to detect resistance mutations [14].

2.4. Statistical Analysis. Statistical analysis was performed using Prism software (GraphPad Software Inc., San Diego, CA, USA). Data are provided as medians and interquartile ranges or as means and standard errors of the mean. Between-group differences were assessed by the Mann-Whitney $U$ test or the $\chi^{2}$ test. The probability of ALT normalization and HBV DNA negativity were examined by the Kaplan-Meier method, and differences were assessed by the log-rank test. Factors associated with ALT normalization and HBV DNA negativity were subjected to univariate and multivariate analyses using the Cox proportional hazards model.

\section{Results}

3.1. Outcomes of ETV Monotherapy. First, we examined the probability of and time to normalization of the ALT level and HBV DNA negativity after 48 or 96 weeks of ETV monotherapy. Among the 130 patients, $89.7 \%$ and $94.1 \%$ achieved ALT normalization after ETV monotherapy for 48 and 96 weeks, respectively (Figure 1(a)). Moreover, 49.2\% and $63.6 \%$ of the patients achieved serum HBV DNA negativity after ETV monotherapy for 48 and 96 weeks, respectively (Figure 1(b)). Next, we divided the patients into an NA-naïve group $(n=108)$ and NA-experienced group $(n=22)$. Of the patients in the NA-naïve group, $89.6 \%$ and 93.1\%, and $48.8 \%$ and $60.4 \%$ achieved ALT normalization and serum HBV DNA negativity after ETV monotherapy for 48 and 96 weeks, respectively. Of the patients in the NAexperienced group, $90.9 \%$ and $100 \%$, and $49.9 \%$ and $74.9 \%$, achieved ALT normalization and serum HBV DNA negativity after ETV monotherapy for 48 and 96 weeks, respectively. There was no significant difference between the NA-naïve and NA-experienced groups in the rate of ALT normalization (Figure 1(c)) or serum HBV DNA negativity (Figure 1(d)).

3.2. Features of Patients with ETV Resistance. Of the 130 patients, $112(86.2 \%)$ were followed for more than 24 weeks. Of the 112 patients, 15 (13.4\%) had resistance to ETV and 97 (86.6\%) did not. The characteristics of the patients are listed in Table 2. The ETV-resistant group were younger and more likely to be male and $\mathrm{HBeAg}$ positive and had significantly higher baseline ALT (Figure 2(a)), HBV DNA (Figure 2(b)), and HBcrAg (Figure 2(c)) levels. However, there was no significant difference between the two groups in prior NA experience, proportion of genotype $\mathrm{C}$ patients, or extent of liver fibrosis. In addition, there was a significant correlation between the serum HBV DNA and ALT levels (Figure 2(d)) and between the serum HBcrAg and ALT levels (Figure 2(e)). There was no significant difference in the time to ALT normalization (Figure 2(f)), but there was a significant difference in the time to HBV DNA negativity after ETV monotherapy in these groups $(p=0.008)$ (Figure $2(\mathrm{~g}))$. 
TABLE 1: Baseline clinical characteristics of ETV monotherapy hepatitis B patients.

\begin{tabular}{lc}
\hline Characteristics & ETV monotherapy $(n=130)$ \\
\hline Age at the beginning (years, (median, IQR)) & $62.0(51.0-71.3)$ \\
Gender (M/F $(n, \%))$ & $72(55.4) / 58(44.6)$ \\
Baseline AST (U/L (median, IQR)) & $37.0(23.8-75.5)$ \\
Baseline ALT (U/L (median, IQR)) & $37.5(22.0-95.5)$ \\
Prior NA exposure (yes/no $(n, \%))$ & $22(16.9) / 108(83.1)$ \\
Baseline HBeAg (+/-/unknown $(n, \%))$ & $51(39.2) / 65(50.0) / 14(10.8)$ \\
Baseline HBV DNA (LogC/mL (median, IQR)) & $5.1(2.5-7.7)$ \\
Baseline HBcrAg (LogU/mL (median, IQR)) & $5.1(3.0-6.8)$ \\
Genotype $(A / B / C / D /$ unknown $(n, \%))$ & $4(3.1) / 14(10.8) / 70(53.8) / 1(0.8) / 41(31.5)$ \\
Fibrosis stage $(F 1 / F 2 / F 3 / F 4 /$ unknown $(n, \%))$ & $7(5.4) / 27(20.8) / 12(9.2) / 3(2.3) / 81(62.3)$ \\
Response to the therapy (resistant/effective/excluded $(n, \%))$ & $15(11.5) / 97(74.6) / 18(13.8)$ \\
\hline
\end{tabular}

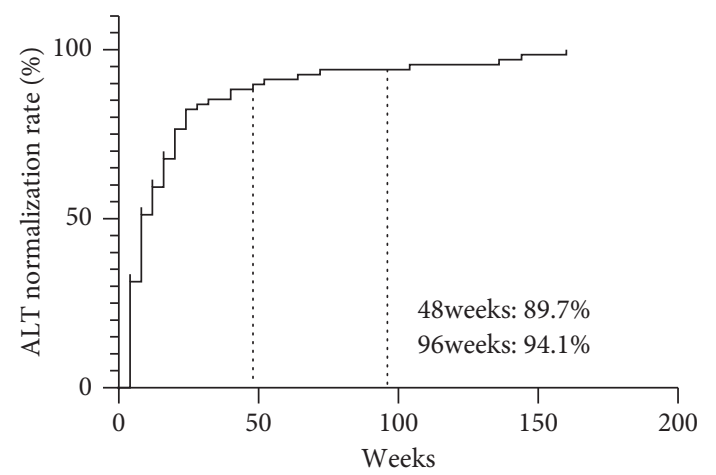

(a)

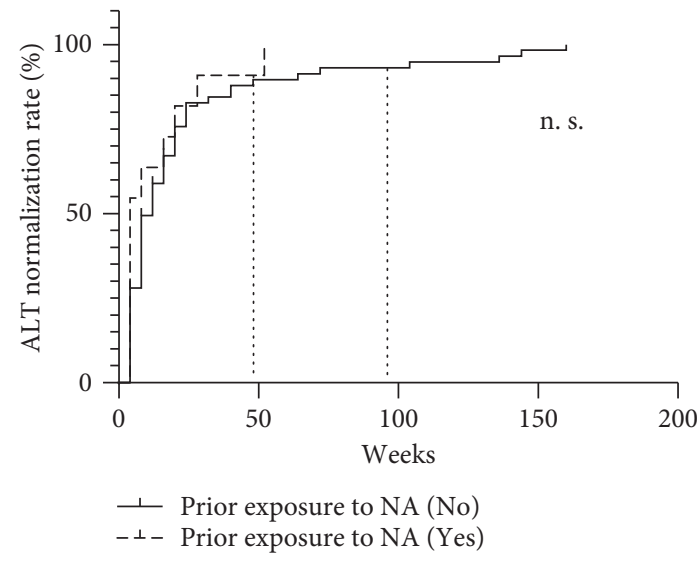

(c)

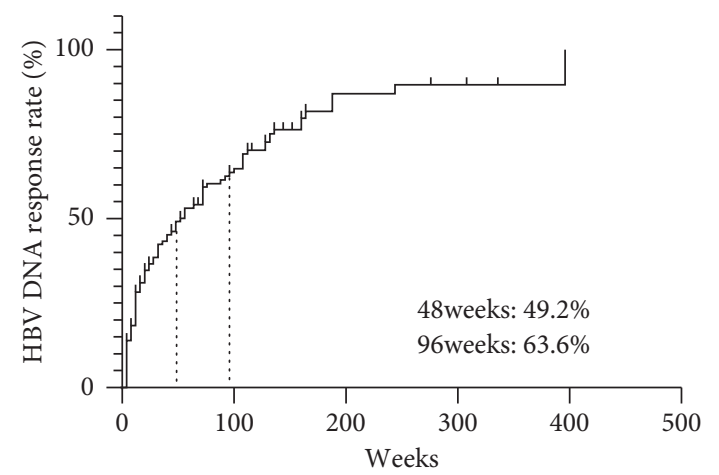

(b)

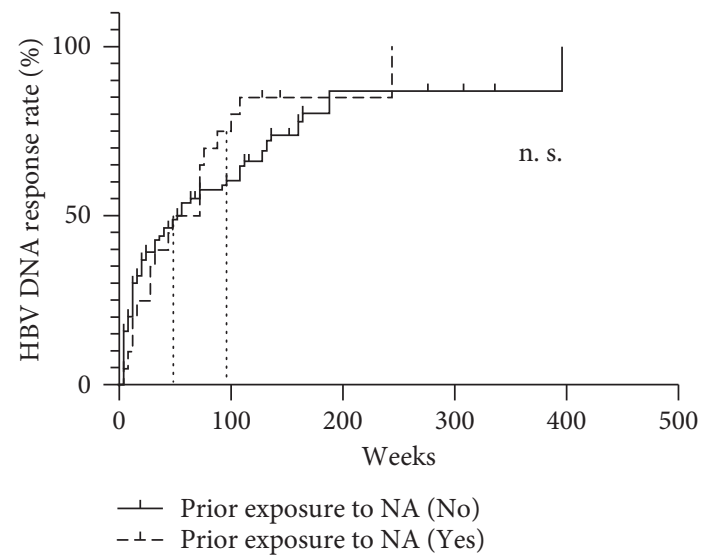

(d)

FIgUre 1: Outcome of ETV monotherapy. Of the 130 patients, ETV monotherapy led to ALT normalization in $89.7 \%$ and $94.1 \%$ after 48 and 96 weeks, respectively (a). ETV monotherapy led to serum HBV DNA negativity in $49.2 \%$ and $63.6 \%$ of the patients at 48 and 96 weeks, respectively (b). There was no significant difference between the NA-naïve group $(n=108)$ and NA-experienced group $(n=22)$ in the rate of ALT normalization (c) or serum HBV DNA negativity (d).

The multivariate analysis of the effect of ETV resistance included the risk factors for ETV resistance in univariate analyses (Table 3 ). Baseline ALT $(\geq 3 \times$ ULN, $p=0.004)$ and $\mathrm{HBcrAg}$ level ( $\geq 5 \log \mathrm{U} / \mathrm{mL}, p=0.013$ ) were significantly associated with ETV resistance (Table 3 ).

3.3. Time to ETV Resistance. Next, we examined the clinical features of the 15 patients with ETV resistance (12 men and
3 women; mean age, $49.1 \pm 12.7$ years) (Tables 4 and 5). Of these patients, 3 and 12 experienced with and naïve to NA therapy, respectively. Although genotypic resistance mutation was not detected in the 15 patients before ETV monotherapy, genotypic resistance (L180M + S202G + $\mathrm{M} 204 \mathrm{~V}$ ) was detected in an NA-naïve patient after NA monotherapy failure.

For the 15 patients with ETV resistance, we added an NA or switched to a different one. For five patients, we added 
TABLE 2: Comparison of clinical and histological characteristics between ETV monotherapy resistant and effective hepatitis B patients.

\begin{tabular}{|c|c|c|c|}
\hline Characteristics & Resistant group $(n=15)$ & Effective group $(n=97)$ & $P$ value \\
\hline Age at the beginning (years (median, IQR)) & $48.0(37.0-61.0)$ & $63.0(54.5-71.0)$ & $P<0.001$ \\
\hline Gender $(\mathrm{M} / \mathrm{F}(n, \%))$ & $12(80.0) / 3(20.0)$ & $48(49.5) / 49(50.5)$ & $P=0.027$ \\
\hline Baseline AST (U/L (median, IQR)) & $65.0(25.0-83.0)$ & $35.0(23.0-64.5)$ & n. s. \\
\hline Baseline ALT (U/L (median, IQR)) & $95.0(34.0-161.0)$ & $36.0(21.0-74.8)$ & $P=0.015$ \\
\hline Prior NA exposure (yes/no $(n, \%))$ & $3(20.0) / 12(80.0)$ & $18(18.6) / 79(81.4)$ & n. s. \\
\hline Baseline HBeAg $(+/-/$ unknown $(n, \%))$ & $10(66.7) / 5(33.3) / 0(0.0)$ & $31(32.0) / 52(53.6) / 14(14.4)$ & $P=0.034$ \\
\hline $\begin{array}{l}\text { Baseline HBV DNA }(\log C / m L \\
\text { (median, IQR)) }\end{array}$ & $7.6(5.4-8.9)$ & $4.4(2.3-7.0)$ & $P<0.001$ \\
\hline Baseline HBcrAg (LogU/mL (median, IQR)) & $6.8(5.9-6.8)$ & $4.1(3.0-6.8)$ & $P=0.003$ \\
\hline Genotype $(A / B / C / D /$ unknown $(n, \%))$ & $\begin{array}{c}0(0.0) / 3(20.0) / 12(80.0) / 0(0.0) / \\
0(0.0)\end{array}$ & $\begin{array}{c}3(3.5) / 10(9.6) / 50(50.4) / 1 \\
(0.9) / 33(40.0)\end{array}$ & n. s. \\
\hline $\begin{array}{l}\text { Fibrosis stage ( } F 1 / F 2 / F 3 / F 4 / \text { unknown ( } n \text {, } \\
\%) \text { ) }\end{array}$ & $\begin{array}{c}3(20.0) / 7(46.7) / 1(6.7) / 1(6.7) / \\
3(20.0)\end{array}$ & $4(4.1) / 19(19.6) / 9(9.3) / 3(3.1) / 62(63.9)$ & n. s. \\
\hline
\end{tabular}

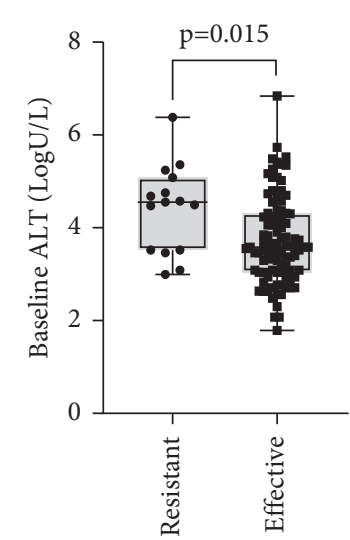

(a)

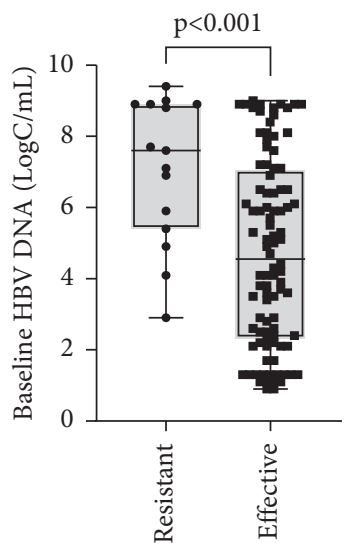

(b)

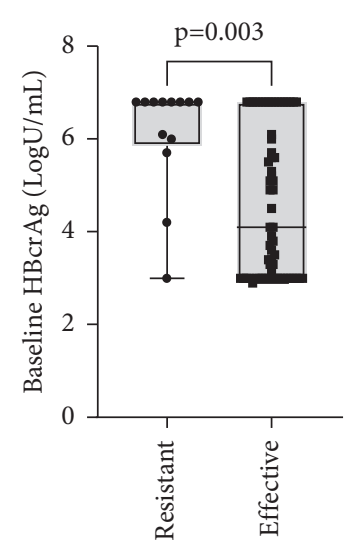

(c)

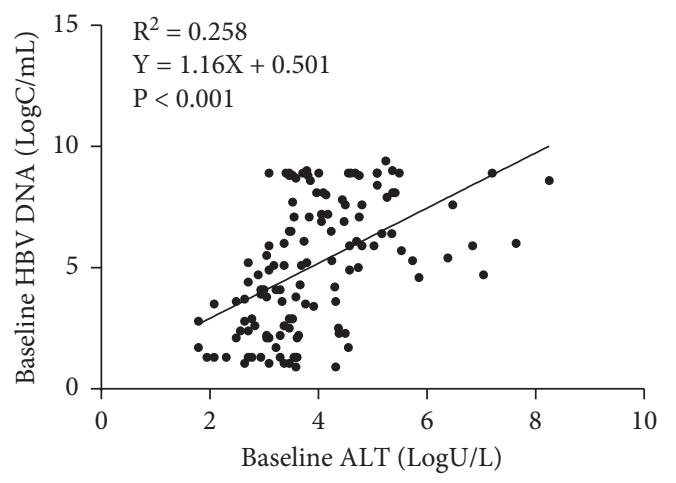

(d)

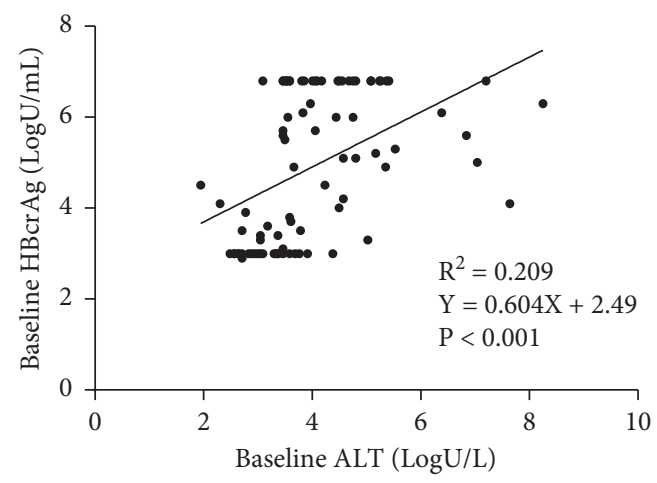

(e)

Figure 2: Continued. 


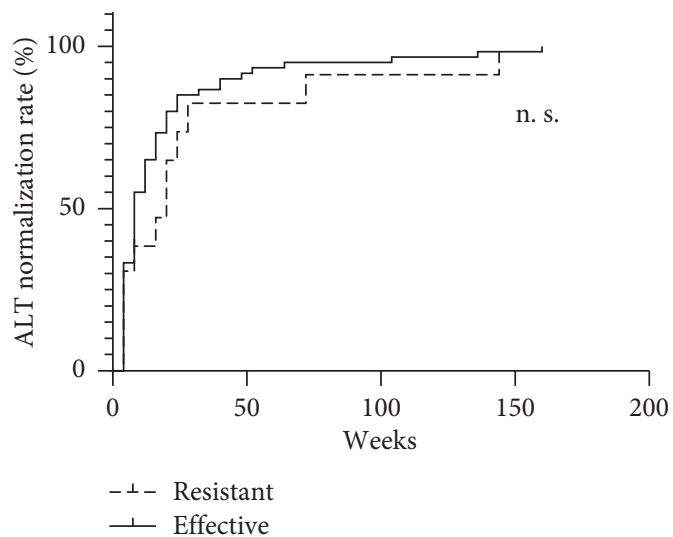

(f)

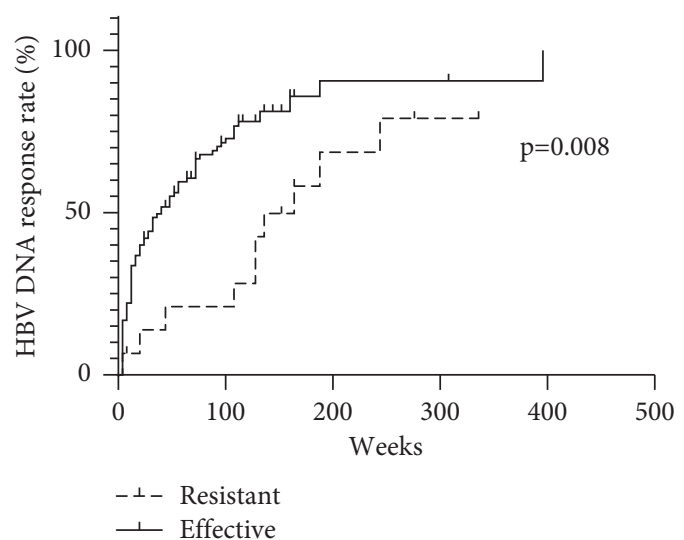

(g)

FIGURE 2: Correlation between time to ETV monotherapy resistance and pretreatment clinical features. In the ETV-resistant group, the proportion of young patients and the ALT (a), HBV DNA (b), and HBcrAg (c) levels at baseline were significantly higher than those in the ETV-responsive group. Baseline ALT levels were significantly correlated with the baseline HBV DNA (d) and HBcrAg (e) levels, irrespective of ETV resistance. There was no significant group difference in the time to ALT normalization (f), but there was a significant group difference in the time to HBV DNA negativity $(p=0.008)(\mathrm{g})$.

TABle 3: Factors contributing to ETV monotherapy resistance (multivariate analysis).

\begin{tabular}{|c|c|c|c|c|}
\hline Characteristics & Univariate OR $(95 \% \mathrm{CI})$ & $P$ value & Multivariate adjusted OR (95\% CI) & $P$ value \\
\hline Age at the beginning ( $<65$ years) & $4.8(1.1-21.9)$ & $P=0.044$ & - & - \\
\hline Gender (male) & $4.1(1.2-14.1)$ & $P=0.049$ & - & - \\
\hline Baseline AST $(\geqq 2 \times$ ULN $)$ & $3.0(0.9-8.3)$ & $P=0.070$ & - & - \\
\hline Baseline ALT $(\geqq 3 \times$ ULN $)$ & $5.4(1.7-17.9)$ & $P=0.004$ & $3.3(0.9-13.6)$ & $P=0.083$ \\
\hline Prior exposure to NA therapies (yes) & $1.1(0.3-4.3)$ & $P>0.999$ & - & - \\
\hline Baseline HBeAg (positive) & $3.4(1.1-9.4)$ & $P=0.047$ & - & - \\
\hline Baseline HBV DNA $(\geqq 5 \log C / m L)$ & $4.4(1.3-15.3)$ & $P=0.025$ & - & - \\
\hline Baseline HBcrAg $(\geqq 5 \log \mathrm{U} / \mathrm{mL})$ & $7.3(1.8-34.5)$ & $P=0.013$ & $4.7(1.0-34.0)$ & $P=0.070$ \\
\hline Genotype C (yes) & $1.1(0.3-4.1)$ & $P>0.999$ & - & - \\
\hline Fibrosis stage $(\leqq F 2)$ & $5.2(0.8-60.9)$ & $P=0.141$ & - & - \\
\hline
\end{tabular}

TABLE 4: Clinical, epidemiologic, and histological characteristics of all ETV-resistant group patients.

\begin{tabular}{|c|c|c|c|c|c|c|c|}
\hline No. & Age (years) & Gender & Prior exposure to NA & Biopsy & Genotype & $\begin{array}{l}\text { Genotypic resistance } \\
\text { (before ETV) }\end{array}$ & Genotypic resistance (after ETV) \\
\hline$\overline{1}$ & 52 & Male & Yes/LAM & $F 3 A 2$ & $\mathrm{C}$ & Negative & Undetectable \\
\hline 2 & 40 & Male & Yes/LAM & $F 1 A 1$ & $\mathrm{C}$ & Undetectable & Undetectable \\
\hline 3 & 30 & Male & $\mathrm{Yes} / \mathrm{LAM}+\mathrm{ADV}$ & $F 2 A 1$ & $\mathrm{C}$ & - & Undetectable \\
\hline 4 & 44 & Male & No & $F 2 A 2$ & $\mathrm{~B}$ & - & - \\
\hline 5 & 76 & Male & No & - & $\mathrm{C}$ & - & Undetectable \\
\hline 6 & 54 & Male & No & - & $\mathrm{B}$ & - & Undetectable \\
\hline 7 & 66 & Male & No & $F 1 A 2$ & $\mathrm{C}$ & - & $\mathrm{L} 180 \mathrm{M}+\mathrm{S} 202 \mathrm{G}+\mathrm{M} 204 \mathrm{~V}$ \\
\hline 8 & 36 & Male & No & $F 2 A 2$ & $\mathrm{C}$ & Negative & Undetectable \\
\hline 9 & 61 & Male & No & $F 4 A 2$ & $\mathrm{~B}$ & Negative & Undetectable \\
\hline 10 & 35 & Male & No & $F 1 A 1$ & $\mathrm{C}$ & - & Undetectable \\
\hline 11 & 37 & Male & No & $F 2 A 2$ & $\mathrm{C}$ & Negative & Undetectable \\
\hline 12 & 61 & Female & No & $F 2 A 2$ & $\mathrm{C}$ & - & Undetectable \\
\hline 13 & 48 & Female & No & $F 2 A 1$ & $\mathrm{C}$ & Negative & Undetectable \\
\hline 14 & 55 & Male & No & - & $\mathrm{C}$ & Negative & Undetectable \\
\hline 15 & 42 & Female & No & $F 2 A 2$ & $\mathrm{C}$ & - & Undetectable \\
\hline
\end{tabular}

TAF (one patients) or TDF (four patients), while nine patients were switched to TAF (eight patients) or TDF (one patient) monotherapy. Also, one patient was switched to
LAM + ADV therapy. The dosage for rescue treatment was the dose listed in the package insert for each drug: $25 \mathrm{mg}$ once daily for TAF, $300 \mathrm{mg}$ once daily for TDF, $100 \mathrm{mg}$ once 
TABLE 5: Clinical, epidemiologic, and histological characteristics of all ETV-resistant group patients (2).

\begin{tabular}{|c|c|c|c|c|c|c|c|c|c|c|}
\hline \multirow[b]{2}{*}{ No. } & \multicolumn{3}{|c|}{ Baseline } & \multirow{2}{*}{$\begin{array}{l}\text { Period to } \\
\text { switch } \\
\text { (months) }\end{array}$} & \multirow[b]{2}{*}{$\begin{array}{c}\text { Rescue } \\
\text { antiviral } \\
\text { treatment }\end{array}$} & \multicolumn{3}{|c|}{ At switch } & \multirow{2}{*}{$\begin{array}{c}\text { ALT }<30 \mathrm{U} / \mathrm{L} \\
\text { after switch } \\
\quad(\text { weeks })\end{array}$} & \multirow{2}{*}{$\begin{array}{c}\text { HBV } \\
\text { DNA }<3 \text { LogC/ } \\
\text { mL after switch } \\
\text { (weeks) }\end{array}$} \\
\hline & $\begin{array}{l}\text { ALT } \\
(\mathrm{U} / \mathrm{L})\end{array}$ & $\begin{array}{l}\text { HBV DNA } \\
(\log C / m L)\end{array}$ & $\begin{array}{c}\text { HBcrAg } \\
(\operatorname{LogU} / \mathrm{mL})\end{array}$ & & & $\begin{array}{l}\text { ALT } \\
(\mathrm{U} / \mathrm{L})\end{array}$ & $\begin{array}{l}\text { HBV DNA } \\
(\operatorname{LogC} / m L)\end{array}$ & $\begin{array}{c}\mathrm{HBcrAg} \\
(\mathrm{LogU} / \\
\mathrm{mL})\end{array}$ & & \\
\hline 1 & 32 & 2.9 & 5.7 & 121 & $\mathrm{ETV}+\mathrm{TDF}$ & 42 & 5.7 & - & 97 & 12 \\
\hline 2 & 20 & 4.1 & 3 & 33 & $\mathrm{LAM}+\mathrm{ADV}$ & 19 & 2.6 & - & - & - \\
\hline 3 & 592 & 5.4 & 6.1 & 33 & TDF & 18 & 2.1 & - & - & - \\
\hline 4 & 116 & 7.1 & 6 & 77 & ETV + TDF & 19 & 4.2 & 3 & - & 8 \\
\hline 5 & 213 & 9 & - & 2 & $\mathrm{ETV}+\mathrm{TDF}$ & 1144 & 8.1 & - & 46 & 20 \\
\hline 6 & 22 & 5.9 & - & 70 & $\mathrm{ETV}+\mathrm{TDF}$ & 19 & 1.7 & 2.9 & - & - \\
\hline 7 & 95 & 8.9 & 6.8 & 42 & $\mathrm{ETV}+\mathrm{TAF}$ & 25 & 6.9 & 7 & - & 24 \\
\hline 8 & 161 & 8.9 & 6.8 & 92 & TAF & 33 & 1.7 & 5.5 & 28 & - \\
\hline 9 & 97 & 4.9 & 4.2 & 137 & TAF & 18 & 1.7 & 2.9 & - & - \\
\hline 10 & 34 & 8.8 & 6.8 & 38 & TAF & 18 & 2.8 & 7 & - & - \\
\hline 11 & 189 & 9.4 & 6.8 & 115 & TAF & 20 & 1.7 & 4.1 & - & - \\
\hline 12 & 34 & 7.7 & 6.8 & 64 & TAF & 10 & 1.7 & 4.9 & - & - \\
\hline 13 & 108 & 8.9 & 6.8 & 84 & TAF & 20 & 1.7 & 5.7 & - & - \\
\hline 14 & 88 & 6.9 & 6.8 & 117 & TAF & 28 & 1.7 & 4 & - & - \\
\hline 15 & 90 & 7.6 & 6.8 & 69 & TAF & 45 & 1.7 & 5.7 & 33 & - \\
\hline
\end{tabular}

daily for LAM, and $10 \mathrm{mg}$ once daily for ADV. However, for patients with impaired renal function, the dose was reduced to the specified level. The median duration of rescue treatment was 36 months (IQR: 25.5-46.5), and HBV DNA and ALT levels were assessed at least once every 3 months.

We analyzed factors associated with the time taken to switch to NA therapy from ETV monotherapy. The baseline ALT (Figure 3(a)), HBV DNA (Figure 3(b)) and HBcrAg (Figure 3(c) levels were not correlated with the time taken to switch to NA therapy. Although ALT elevation was observed in four patients, switching to NA therapy led to its normalization (mean, 51.0 \pm 27.4 weeks). HBV DNA elevation (>3.0 $\log \mathrm{U} / \mathrm{mL}$ ) was also observed in four patients, but all of them achieved an HBV DNA level of $<3.0 \log \mathrm{U} / \mathrm{mL}$ (mean, $16.0 \pm 6.3$ weeks).

3.4. Differences between the NA-Naïve and NA-Experienced Groups in Patients with ETV Resistance. There were significant differences between the NA-naïve and NA-experienced groups in pretreatment HBV DNA $(p=0.011)$ and HBcrAg $(p=0.021)$ levels (Table 6). The NA-experienced HBV patients showed a tendency toward ETV resistance even with a low HBV viral load.

\section{Discussion}

Although most patients with $\mathrm{HBV}$ infection who receive ETV monotherapy have a benign clinical course, some develop ETV resistance. A major concern with long-term NA treatment is antiviral resistance mutations. ETV, the first approved oral NA, develops resistance at a very low rate in treatment-naïve patients, although the rate of ETV resistance increases to $51 \%$ in patients with resistance to LAM [9]. Thus, detecting resistant variants is critical for appropriate patient treatment, and some substitutions have been characterized in an ETV-refractory patient, which mediated ETV resistance by significantly reducing viral replication
[15]. However, evaluating all known resistance mutations is difficult, expensive, and time-consuming [16]. In fact, we detected genetic resistance mutation in only one patient in this study, although the PCR-Invader assay reported that $50.6 \%$ of the samples were positive for ETV resistance mutations [14]. Therefore, physicians should monitor the HBV viral load even without examining resistance variants because the rate of viral suppression increases over time and the time required for treatment adaptation depends on viral load decay, especially in patients starting from a very high viral load who may need therapy for a few more weeks to achieve an undetectable HBV DNA level. A persistent low viremia level and plateau thereof indicate a need for treatment optimization to maximize viral suppression and minimize the subsequent risk of resistance [17]. The AASLD guidelines state that the rate at which resistant variants are selected is related to the pretreatment serum HBV DNA level, rapidity of viral suppression, duration of treatment, prior exposure to NA therapies, and most importantly, the genetic barrier to resistance of the NA [5]. Our results also suggested that patients with a high pretreatment HBV DNA viral load tend to develop resistance to ETV.

ETV is associated with resistance in LAM-experienced (particularly LAM-refractory) patients, and bone and renal safety issues are a concern with $\operatorname{TDF}[18,19]$. Therefore, it has been proposed that optimizing the use of TAF is suitable for NA therapy along with guidance on specific patient groups at risk of renal or bone disease LAM-experienced patients $[20,21]$. As for ETV, it has a large number of accumulating evidences, usage experiences, and cost effectiveness. It will likely continue to be the first-line NAs for HBV infection, except for LAM-experienced patients and those with a high pretreatment HBV viral load.

In this study, 15 patients had to switch to other NAs because of resistance to ETV. The choice of rescue NA therapy has been widened due to the availability of new NAs. Tenofovir (TDF or TAF) is added to ETV monotherapy in the presence of ETV resistance, as the preferred strategy to 


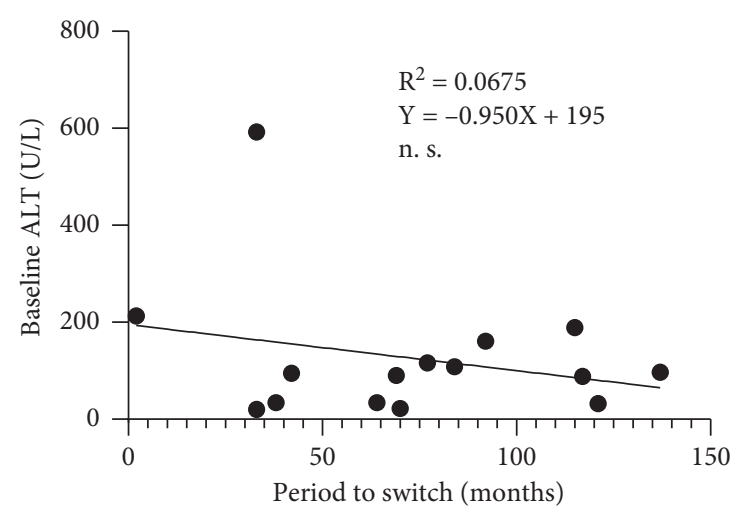

(a)

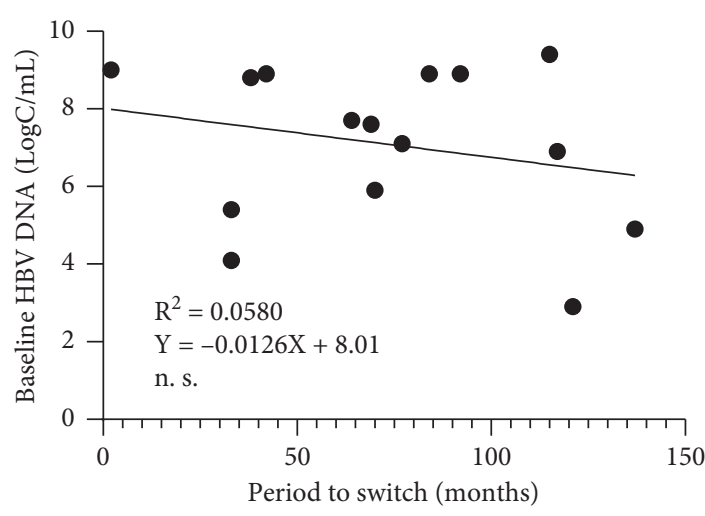

(b)

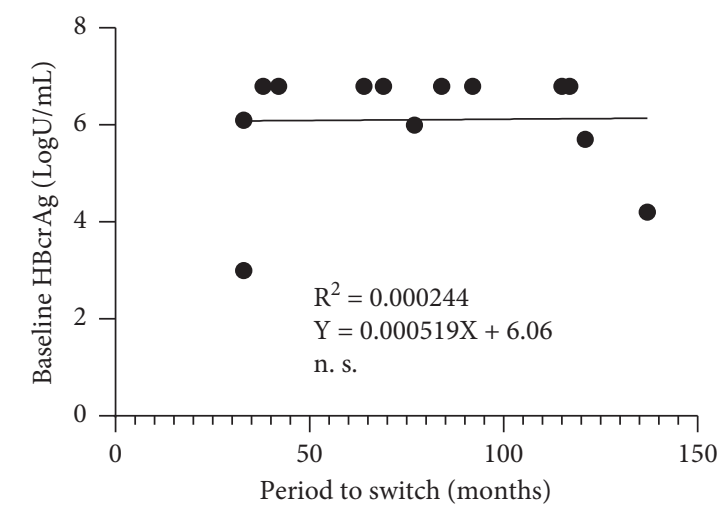

(c)

FIGURE 3: Factors associated with the time taken to switch to NA therapy from ETV monotherapy. The baseline ALT (a), HBV DNA (b), and HBcrAg (c) levels were not significantly correlated with the time taken to switch to NA therapy.

TABLE 6: Comparison of clinical characteristics of ETV-resistant hepatitis B patients between NA-naïve patients and patients with prior NA exposure.

\begin{tabular}{|c|c|c|c|}
\hline Characteristics & NA naive patients $(n=12)$ & $\begin{array}{l}\text { Patients with prior NA exposure } \\
\qquad(n=3)\end{array}$ & $P$ value \\
\hline Age at the beginning (years) & $51.3 \pm 12.6$ & $40.7 \pm 9.0$ & n. s. \\
\hline Gender $(\mathrm{M} / \mathrm{F}(n, \%))$ & $9(75) / 3(25)$ & $3(100) / 0(0)$ & n. s. \\
\hline Baseline AST (U/L) & $64.1 \pm 29.2$ & $84.0 \pm 87.0$ & n. s. \\
\hline Baseline ALT (U/L) & $103.9 \pm 57.5$ & $214.7 \pm 266.9$ & n. s. \\
\hline Baseline HBV DNA $(\log C / m L)$ & $7.8 \pm 1.4$ & $4.1 \pm 1.0$ & $P=0.011$ \\
\hline Baseline HBeAg $(+/-(n, \%))$ & $8(66.6) / 4(33.3)$ & $2(66.6) / 1(33.3)$ & n. s. \\
\hline Baseline HBcrAg (Log U/mL) & $6.5 \pm 0.8$ & $4.9 \pm 1.4$ & $P=0.021$ \\
\hline Genotype $(B / C(n, \%))$ & $3(25.0) / 9(75.0)$ & $0(0.0) / 3(100.0)$ & n. s. \\
\hline $\operatorname{HCC}(n, \%)$ & $2(16.7)$ & $0(0)$ & n. s. \\
\hline Fibrosis stage $(F 1 / F 2 / F 3 / F 4 /$ unknown $(n, \%))$ & $\begin{array}{c}2(16.7) / 6(50.0) / 0(0.0) / 1 \\
(8.3) / 3(25.0)\end{array}$ & $\begin{array}{c}1(33.3) / 1(33.3) / 1(33.3) / 0 \\
(0.0) / 0(0.0)\end{array}$ & n. s. \\
\hline Period to next treatment (months) & $75.6 \pm 36.0$ & $62.3 \pm 41.5$ & n. s. \\
\hline $\begin{array}{l}\text { Genotypic resistance (after ETV) (detected/undetectable/ } \\
\text { no sample }(n, \%) \text { ) }\end{array}$ & $1(8.3) / 10(83.3) / 1(8.3)$ & $0(0.0) / 3(100.0) / 0(0.0)$ & n. s. \\
\hline
\end{tabular}

control viral replication in the majority of patients in whom liver disease progression is attenuated [22]. In particular, TAF monotherapy is used as rescue therapy to normalize ALT; TAF is preferred because it has fewer adverse effects (such as renal and bone damage) than TDF.

This study had several limitations. First, the indications for ETV monotherapy for HBV infection have changed due to the development of TDF and TAF, but ETV monotherapy is even now the first-line regimen for $\mathrm{HBV}$ infection in Japan. Second, this was a retrospective medical record-based study performed at a single center, the sample size was small, and the detailed drinking history was not reviewed. In addition, it may be possible that there is a problem with drug adherence because the percentage of ETV resistance emerged in this study was higher than previously reported. 
In conclusion, patients with HBV hepatitis who received ETV monotherapy had satisfactory outcomes. If the pretreatment HBV DNA viral load is high, the serum HBV DNA and ALT levels should be more carefully monitored, and TAF therapy shall be taken in account in the future.

\section{Data Availability}

In order to protect personal information, the authors refrain from publishing patient-specific raw data beyond the data in table.

\section{Conflicts of Interest}

The authors declare that they have no conflicts of interest.

\section{Acknowledgments}

The authors would like to thank all of the patients and the staff of participating institutions.

\section{References}

[1] I. Chemin and F. Zoulim, "Hepatitis B virus induced hepatocellular carcinoma," Cancer Letters, vol. 286, no. 1, pp. 52-59, 2009.

[2] C. Trépo, H. L. Y. Chan, and A. Lok, "Hepatitis B virus infection," The Lancet, vol. 384, no. 9959, pp. 2053-2063, 2014.

[3] L. Bucci, F. Garuti, B. Lenzi et al., "The evolutionary scenario of hepatocellular carcinoma in Italy: an update," Liver International, vol. 37, no. 2, pp. 259-270, 2017.

[4] G. Bedogni, L. Miglioli, F. Masutti et al., "Natural course of chronic HCV and HBV infection and role of alcohol in the general population: the dionysos study," The American Journal of Gastroenterology, vol. 103, no. 9, pp. 2248-2253, 2008.

[5] N. A. Terrault, A. S. F. Lok, B. J. McMahon et al., "Update on prevention, diagnosis, and treatment of chronic hepatitis $B$ : AASLD 2018 hepatitis B guidance," Hepatology, vol. 67, no. 4, pp. 1560-1599, 2018.

[6] European Association for the Study of the Liver, "European association for the study of the liver. EASL 2017 clinical practice guidelines on the management of hepatitis $B$ virus infection," Journal of Hepatology, vol. 67, pp. 370-398, 2017.

[7] S. K. Sarin, M. Kumar, G. K. Lau et al., "Asian-Pacific clinical practice guidelines on the management of hepatitis B: a 2015 update," Hepatology International, vol. 10, no. 1, pp. 1-98, 2016.

[8] Drafting Committee for Hepatitis Management Guidelines and the Japan Society of Hepatology, "JSH guidelines for the management of hepatitis B virus infection," Hepatology Research, vol. 44, pp. 1-58, 2014.

[9] F. Zoulim and S. Locarnini, "Hepatitis B virus resistance to nucleos(t)ide analogues," Gastroenterology, vol. 137, no. 5, pp. 1593-1608, 2009.

[10] L. Menéndez-Arias, M. Álvarez, and B. Pacheco, "Nucleoside/ nucleotide analog inhibitors of hepatitis B virus polymerase: mechanism of action and resistance," Current Opinion in Virology, vol. 8, pp. 1-9, 2014.

[11] T.-T. Chang, R. G. Gish, R. de Man et al., "A comparison of entecavir and lamivudine for HBeAg-positive chronic hepatitis B," New England Journal of Medicine, vol. 354, no. 10, pp. 1001-1010, 2006.
[12] C.-L. Lai, D. Shouval, A. S. Lok et al., "Entecavir versus lamivudine for patients with $\mathrm{HBeAg-negative} \mathrm{chronic} \mathrm{hep-}$ atitis B," New England Journal of Medicine, vol. 354, no. 10, pp. 1011-1020, 2006.

[13] A. Ono, F. Suzuki, Y. Kawamura et al., "Long-term continuous entecavir therapy in nucleos(t)ide-naïve chronic hepatitis B patients," Journal of Hepatology, vol. 57, no. 3, pp. 508-514, 2012.

[14] K. Tadokoro, F. Suzuki, M. Kobayashi et al., "Rapid detection of drug-resistant mutations in hepatitis B virus by the PCRInvader assay," Journal of Virological Methods, vol. 171, no. 1, pp. 67-73, 2011.

[15] T. Shaw, A. Bartholomeusz, and S. Locarnini, "HBV drug resistance: mechanisms, detection and interpretation," Journal of Hepatology, vol. 44, no. 3, pp. 593-606, 2006.

[16] S. Hayashi, S. Murakami, K. Omagari et al., "Characterization of novel entecavir resistance mutations," Journal of Hepatology, vol. 63, no. 3, pp. 546-553, 2015.

[17] E. B. Keeffe, S. Zeuzem, R. S. Koff et al., "Report of an international workshop: roadmap for management of patients receiving oral therapy for chronic hepatitis B," Clinical Gastroenterology and Hepatology, vol. 5, no. 8, pp. 890-897, 2007.

[18] M. Viganò, A. Loglio, G. Grossi, and P. Lampertico, "Tenofovir alafenamide (TAF) treatment of HBV, what are the unanswered questions?" Expert Review of Anti-Infective Therapy, vol. 16, no. 2, pp. 153-161, 2018.

[19] S. Abdul Basit, A. Dawood, J. Ryan, and R. Gish, "Tenofovir alafenamide for the treatment of chronic hepatitis B virus infection," Expert Review of Clinical Pharmacology, vol. 10, no. 7, pp. 707-716, 2017.

[20] E. Ogawa, N. Furusyo, and M. H. Nguyen, "Tenofovir alafenamide in the treatment of chronic hepatitis B: design, development, and place in therapy," Drug Design, Development and Therapy, vol. 11, pp. 3197-3204, 2017.

[21] M. R. Charlton, A. Alam, A. Shukla et al., "An expert review on the use of tenofovir alafenamide for the treatment of chronic hepatitis B virus infection in Asia," Journal of Gastroenterology, vol. 55, no. 9, pp. 811-823, 2020.

[22] L. Kang, J. Pan, J. Wu, J. Hu, Q. Sun, and J. Tang, "Anti-HBV drugs: progress, unmet needs, and new hope," Viruses, vol. 7, no. 9, pp. 4960-4977, 2015. 